\title{
Integrated Mathematics Enrichment, Peer Mentoring, Tutoring, and Fresh- men Course for Student Success
}

Dr. Cem Karacal, Southern Illinois University, Edwardsville

Dr. Cem Karacal is a Professor of Industrial Engineering and Dean of the School of Engineering at Southern Illinois University Edwardsville. He obtained his Ph.D. and M.S. degrees from Oklahoma State University in 1991 and 1986, respectively. His received his B.Sc. degree from Middle East Technical University, Ankara, Turkey in 1982. He has experience in industry and academia. His main research and teaching interest areas are simulation modeling, quality control, operations research, and facilities layout. $\mathrm{He}$ is a senior member of IIE and SME, and a member of ASEE, Alpha Pi Mu and Tau Beta Pi.

Dr. Ma Zenia N. Agustin, Southern Illinois University, Edwardsville

Dr. Zenia Agustin is a Professor in the Department of Mathematics and Statistics at Southern Illinois University Edwardsville. Currently, she is the Director of General Education and Integrative Studies for the university and Director of the Actuarial Science program for the department. Her research interests include reliability and survival analysis and in particular, goodness-of-fit testing for recurrent events.

\section{Prof. George Pelekanos, Southern Illinois University, Edwardsville}

Dr. George Pelekanos is a Professor in the Department of Mathematics and Statistics at Southern Illinois University Edwardsville. He obtained his Ph. D degree in Applied Mathematics from the University of Delaware in 1997. His research interests include inverse scattering and mathematics education. 


\title{
An Integrated Mathematics Enrichment, Peer-Mentoring, Tutoring and Freshman Course for Student Success
}

\author{
Cem Karacal ${ }^{1}$, Zenia Agustin ${ }^{2}$, George Pelekanos ${ }^{2}$ \\ skaraca@siue.edu, zagusti@siue.edu, gpeleka@siue.edu \\ Southern Illinois University Edwardsville \\ School of Engineering ${ }^{1}$, College of Arts \& Sciences, Mathematics \& Statistics Department ${ }^{2}$ \\ Edwardsville, IL 62026
}

\begin{abstract}
This Evidence-based practice complete paper describes the experiences with a holistic Mathematics Enrichment Sessions, Freshmen Mentoring, Mathematics Tutoring and new Freshmen Engineering course that are implemented during the last five years at Southern Illinois University Edwardsville as part of our NSF STEP project. The mathematics Enrichment Session (ES) idea, which is a combination of the best aspects of Supplemental Instruction idea and PeerLed Team Learning methods, can be an effective way of supporting students in their first year of studies. The implementation of the peer-mentoring program that was originally envisioned as a residence hall mentoring program has proven to be more challenging than planned and modified based on our student characteristics and demographics. Online and faceto-face mathematics tutoring programs are implemented and their utilization levels are monitored. As part of the project, the freshmen engineering course is revamped and its outcomes are discussed.
\end{abstract}

\section{Introduction}

According to the U.S. Bureau of Labor Statistics projections, demand for engineering disciplines will experience noteworthy growth in the coming years. As the interest in engineering education in the U.S. remains relatively steady over the last few decades, the implications of projected growth can have serious consequences for the well-being of the economy and the society. Furthermore, the number of engineering degrees awarded to underrepresented groups has ample room to reach to desired levels. The recruitment and retention of engineering students, especially those from underrepresented groups, play a strategically important role for the future well-being of the nation [1,2]. Universities have to take necessary steps to create a nurturing learning environment where students of various backgrounds and skill levels are provided support systems that give them opportunities for success in a rigorous engineering curriculum.

Our integrated approach for student success is based on 4 major components, namely, enhancement to the delivery of Calculus I and Calculus II courses, peer-mentoring, tutoring and a revised version of the freshman engineering course. Research has shown that one of the major barriers to retention for students interested in STEM majors is their performance in their early mathematics courses such as Calculus I [3]. Failure to complete Calculus I successfully is a 
strong determinant in a student's decision to remain an engineering major or even to stay at a university. It is therefore imperative to provide students with a strong foundation in the first semester Calculus I and to provide the necessary support in order for them to be successful. Peer mentoring has proven to be an effective tool to engage freshmen with the engineering community and student organizations. The students who develop strong social networks and become active participants of student organizations persist better in their studies. Peer mentors play an important role in facilitating such connections. Mathematics tutoring services offered strategically at freshmen residence hall in early evening hours provide additional support beyond lectures and enrichment sessions and help students with homework assignments and test preparations. Finally, we have developed a modular and project based version of our existing freshman engineering course. The course also serves as a retention tool as it invokes a lasting interest in engineering. Furthermore, it facilitates students' understanding of the engineering disciplines offered in the school and help them make an informed decision when deciding on their specific study area. [4]

\section{Major Project Activities:}

\section{The Mathematics Enrichment Sessions}

The mathematics Enrichment Session (ES) approach taken in this study employs a learning model that engages small groups of students to solve problems in a collaborative manner, with trained undergraduate students called ES Leaders acting as facilitators. Eighty minute-long ES sessions that appear on the students' schedules are held on Tuesdays and Thursdays, while instructor lectures are on Mondays, Wednesdays, and Fridays.

The project team has two mathematics professors and worked with the Mathematics department administration to set up the class schedules and arrange rooms for the enrichment sections. The results from the first year of project implementation indicated that MATH 125 Pre-Calculus with Trigonometry did not yield the expected improvement on the passing rates when ES sections are compared to sections without ES. The student profile of the declared engineering students who qualified for the MATH 125 course made it a real challenge to register these students in one section. Most of these students were aware of their deficiency in mathematics and do not have the same dedication to study engineering as those who qualified for Calculus I or higher. The extra hours they needed to spend in Enrichment Sessions was a deterrent for many, especially for those who were holding part-time jobs. Despite our best efforts to register them together, majority opt out of the engineering section with enrichment and registered for regular PreCalculus sections with the intent that they might switch majors in the future.

In addition, the project team and the academic advisors made the observation that many of these students were hesitant due to stiffer competition they will have in the engineering section of PreCalculus as they felt less confident about their own math skills. As a result, the project team decided to concentrate the efforts on where the biggest gains were achieved by offering ES in 
Calculus I and Calculus II only. Therefore only the following courses are supported through ES sessions in the following academic years.

Fall semesters: Two engineering sections of MATH 150, Calculus I, each with 60 seats

Spring semesters: One engineering section of MATH 150, Calculus I, with 60 seats

Two engineering sections of MATH 152, Calculus II, each with 60 seats

The instructors of these sections worked with the project team and facilitated the activities of the enrichment sessions corresponding to their lectures. The ES leaders coordinated a schedule among themselves to ensure ES leader attendance to the lectures so close coordination between lectures and Enrichment Sessions is achieved.

In each academic year, around 12 ES leaders were hired, most of whom were returning students with good track record as ES leaders. The group typically included female and/or underrepresented students. The project team consulted with the mathematics professors who taught Calculus I and II in previous academic years and identified a group of engineering students as good candidates for open ES leader positions that are vacated due to graduation. The interviews included a section in which the candidate gave a brief presentation on the limit definition of derivative. The team assessed candidate's knowledge of the material, communication skills as well as personality. After a set of interviews, new students are added to the ES leader group. The project team organized an orientation sessions for the ES leaders to explain fundamentals of group dynamics, how to facilitate student learning in ES sessions and the ground rules of the program. They are were also given background on the record keeping and reporting system used for the project. Weekly ES Leader meetings were held where student performance and struggles were discussed. The feedback from ES Leaders were used to inform the development of subsequent ES worksheet problems.

The project team coordinated with the instructors of the Engineering sections of Calculus and developed the ES worksheets. An older version of the worksheets is available at the following websites:

MATH 150 - Calculus I:

https://www.dropbox.com/sh/20c1r5xly4hr5iz/AADxCqGrIaKYmrjexzsdNU0Ka

MATH 152 - Calculus II:

https://www.dropbox.com/sh/2ytb1pk0jpkvjk1/AAANU0ltAOOYo3px2BifGWb_a

During each ES meeting, students are divided into groups of 4 or 5 and are provided worksheets that contained both computational and conceptual problems. The problems in each worksheet covered material that was discussed in the related lecture as well as previous topics that students usually struggled with. Students are assigned to a different group each week so they get to know more people in the class and be able to make connections. Thus, in addition to academic support, ES provided opportunities for social networking. Group members work through the problems 
together while the ES Leaders move around the room answering questions and making sure that all students are actively participating. Even though each group worked together to solve the problems, each student submitted his/her own worksheet which was graded separately. Attendance at ES is required and worksheet grades count as a small part of the course grade, typically $5 \%$. In order to dispel any thought of using the ES as a substitute for the regular class meeting, students who miss a regular class meeting were not eligible to participate in the corresponding ES meeting.

\section{Peer Mentoring}

The peer-mentoring program initially envisioned as a Residence Hall Mentoring program is revised to serve the objectives of the project better after the first year. The program is expanded to all engineering freshmen to increase participation level. After experimenting with a few other ideas such as project based mentoring, we have decided to use a traditional academic/social interaction based mentoring program. The design-build project centered mentoring program worked really well for a relatively limited number of highly motivated students, but unfortunately, the time and effort required in the projects were deterrents to several others once they got busy with their courses. Furthermore, the canned project challenges presented to mentees was not the right approach to capture student's interest or passion for the hands-on project based mentoring idea. In year five, we have tried student initiated project ideas, but once again, when the semester was in full swing students failed to follow through their project ideas.

Most of our experienced mentors graduated a few years after the initial implementation of the peer-mentoring program. In the later years of the project, we brought in new mentors some of whom were participants of the mentoring program as mentees in previous years. These student mentors were all in good academic standing from various engineering programs with sound interpersonal skills. There were several females in the group every year. These mentors were trained in effective mentoring strategies via an orientation meeting in which program objectives and ground rules are communicated. In addition, they were given pointers on how to properly engage and interact with mentees along with reminders about university's housing/campus rules and a set of suggested academic/social activities. The Mentors kept a log-book of their activities and attended mentor meetings with some of the senior project team members on a periodic basis. Given the expected participation rate, each mentor was asked to make as many connections as they can with their 30 assigned mentees, and to lead a study group at least once a week. Each mentor worked about 6 hours a week to interact with students on a personal basis and organized a social event or a cultural/sports activity on or off campus once a month. In addition, they helped their mentees learn about campus and school of engineering resources such as tutoring, writing center, counseling, student design teams and professional societies.

On average, about 120-150 engineering first-year students live in the engineering Focused Interest Community (FIC) of the freshman Residence Hall each academic year. Almost all 
engineering FIC residents are participants of the mentoring program. As a result, the program used the freshman Hall as the home base. The Residence Hall lounges, classrooms and multifunction room are used to organize activities and study sessions that made access to program events especially convenient for Engineering FIC residents.

\section{Tutoring}

The mathematics ES sessions are reinforced through a tutoring program that was easy to access. Initially, both face-to-face and online tutoring services were provided by undergraduate engineering peers. While the university's math resources center provides tutoring services to all students during daytime in the Student Success Center, face-to-face engineering tutors supported via this project were stationed in the freshman residence hall every day from 6-9 pm, except Fridays and Saturdays. The tutors are recruited using a process very similar to ES leaders. The quick review of the tutor's logbook records for the first year indicated that the utilization rate of online tutoring was disappointingly low. The online tutoring was originally offered as a followup to face-to-face tutoring and was scheduled between 9 and $11 \mathrm{pm}$. The Skype was used as the platform for online connection with the tutor. The feedback received from the students indicated that some were conscious about their appearances while studying in their rooms and were hesitant to use the video conferencing services. As a result, we have subscribed to an online software called Tutorbox where video connection was an option in the following year.

Nevertheless, the utilization rate for the service did not improve and we decided to cancel the online tutoring services after the second year. Each semester, a good number of students enrolled in Calculus I or Calculus II took advantage of the face-to-face tutoring services. The tutors made a note of the topics the students were struggling with the most and communicated those to the instructors of the Calculus I or Calculus II engineering sections.

\section{Freshman Engineering Course}

The Engineering freshman course called Engineering Problem Solving was redesigned in the first year of the project to better engage with students. The course is offered both in fall and spring semesters in four sections and each section is limited to 32 students to provide meaningful interaction between students and the instructors. The engineering students who sign up for the university's Springboard to Success New Student Orientation program as well as those who transfer in or declare their majors before the semester starts take the course. The four instructors of the course organized the course content in four different modules that represent the main engineering disciplines offered in the school, namely, civil, mechanical, industrial, and electrical engineering. Each module is about 4 weeks long and requires a hands-on project that is intertwined with discipline specific lectures. The instructors are some of our most effective teachers from aforementioned engineering disciplines and rotate between sections to repeat their modules. This format improves student's understanding of different disciplines and gives students an opportunity to get acquainted with engineering professors early in their 
studies. Some of our declared engineering freshmen, even if they have an inclination towards a particular engineering discipline, do not commit to a particular discipline when they begin their studies. This course helps them form a better opinion about different engineering disciplines and facilitates making a better selection that fits their interest.

In the following years of the project, we have offered a $5^{\text {th }}$ section with $40-60$ seats to those students who are interested in engineering but not yet eligible to declare or has not declared engineering as their major. Although a single instructor offers the course, the course content and the hands-on projects are coordinated with the aforementioned sections to ensure that similar topics are covered. We have also offered a summer section of this course to newly admitted engineering students who wanted to make a head start in their studies.

\section{Summary of Project Results:}

\section{Mathematics Enrichment Sessions}

The performance of students who opted to register for the ES sections are compared to those who chose the non-ES sections. Non-ES sections have either the traditional recitation sessions or computer laboratories that use the software Mathematica. Graduate teaching assistants conduct both of these options. The results from the initial implementation of ES are presented in [5].

To gauge the effectiveness of the ES approach, the ES group and the non-ES group were compared relative to two measures: proportion of students who passed Calculus $\mathrm{I}$, that is proportion who earned letter grades of $\mathrm{A}, \mathrm{B}$, or $\mathrm{C}$ and proportion of students who earned grades of A or B. It has been shown in the literature that students who earn grades of at least B in Calculus I tend to perform better in subsequent mathematics and physics courses ${ }^{3}$. In this paper, the results for Calculus I during the fall semesters of the five-year project are presented. The population of students who register for Calculus I during fall semesters differ significantly from the population of students who register during spring semesters. Spring semester Calculus I students are typically those who are repeating the course or those who are coming from PreCalculus. On average, 100 engineering students registered in ES sections of Calculus I in fall semesters. The results over the five-year period are presented in Table 1, where the $p$-value corresponds to a one-sided test for two proportions. The proportion of freshman engineering majors who completed Calculus I with a grade of at least $\mathrm{C}$ is significantly higher for the ES group compared to the non-ES group. In addition, the proportion of engineering majors who earn grades of at least B is also significantly higher for the ES group compared to the non-ES group. It is also worth noting that the withdrawal rate of the ES group is significantly lower than that of the non-ES group. 
Table 1: Calculus I - Comparison between ES and non-ES groups

\begin{tabular}{|c|c|c|c|c|}
\hline & ES & Non-ES & Test Statistic & $p$-value \\
\hline $\begin{array}{c}\text { Proportion of students who } \\
\text { earned grades of A, B, or C }\end{array}$ & 0.664 & 0.491 & 6.74 & $<0.001$ \\
\hline $\begin{array}{c}\text { Proportion of students who } \\
\text { earned grades of A or B }\end{array}$ & 0.459 & 0.289 & 6.55 & $<0.001$ \\
\hline $\begin{array}{c}\text { Proportion of students who } \\
\text { withdrew from the course }\end{array}$ & 0.159 & 0.210 & -2.51 & 0.006 \\
\hline
\end{tabular}

Since students were not randomly assigned to the ES sections, it is important to consider whether there are other factors that can play a role in their performance in Calculus I. For freshman students, ACT score is typically a factor that is considered. For this paper, the ACT Math subscore is considered since this was used as a basis for placing into Calculus I. Complete ACT Math sub-score information is readily available for the first cohort of students in Fall 2013 who participated in the Springboard to Success New Student Orientation program. The results for this cohort of students are presented in Table 2. The $p$-value for the test concerning the ACT Math sub score corresponds to a two-sided test, while the one for the passing rate corresponds to a onesided test. Note that there is no statistically significant difference in the mean ACT Mat subscore for the two groups, but the proportion of students who earned grades of at least $\mathrm{C}$ is significantly higher for the ES group at a 10\% significance level.

Table 2: Calculus I Fall 2013 Cohort - Comparison between ES and non-ES groups

\begin{tabular}{|c|c|c|c|c|}
\hline & ES & Non-ES & Test Statistic & $\boldsymbol{p}$-value \\
\hline ACT Math sub-score & 29.09 & 29.41 & 0.52 & 0.601 \\
\hline $\begin{array}{l}\text { Proportion of students who } \\
\text { earned grades of A, B, or C }\end{array}$ & 0.826 & 0.676 & -1.53 & 0.063 \\
\hline
\end{tabular}

The results for the Calculus II ES sections over the five-year period are summarized in Table 3. On average, 100 engineering students populated the two ES sections of Calculus II each spring semester. In all three categories, the one-sided tests were statistically significant. Thus, the proportion of students who earned grades of A, B or C in the ES group is significantly higher than the proportion of students who passed in the non-ES group. The same relationship is true if we look at the proportion of students who earned grades of A or B. On the other hand, the proportion of students who withdrew from the course is significantly lower for the ES group compared to the non-ES group. Overall, students in Calculus II who had ES had a higher passing rate, a higher rate of grades of $\mathrm{A}$ or $\mathrm{B}$, and a lower rate of withdrawals from the course compared to those in the non-ES group. 
Table 3: Calculus II - Comparison between ES and non-ES groups

\begin{tabular}{|c|c|c|c|c|}
\hline & ES & Non-ES & Test Statistic & $\boldsymbol{p}$-value \\
\hline $\begin{array}{c}\text { Proportion of students who } \\
\text { earned grades of A, B, or C }\end{array}$ & 0.686 & 0.570 & 4.01 & $<0.001$ \\
\hline $\begin{array}{c}\text { Proportion of students who } \\
\text { earned grades of A or B }\end{array}$ & 0.404 & 0.302 & 3.59 & $<0.001$ \\
\hline $\begin{array}{c}\text { Proportion of students who } \\
\text { withdrew from the course }\end{array}$ & 0.135 & 0.192 & -2.60 & 0.005 \\
\hline
\end{tabular}

\section{Peer-Mentoring Program}

The first year implementation of the peer-mentoring program presented challenges. After realizing the difficulty of finding upper classmen willing to live in the freshman residence halls with the level of support that the project allowed us to provide to mentors, we recruited mentors who had previous university housing experience, but not necessarily lived in the residence halls. The difficulty of finding qualified mentors from the junior and senior cohorts during the following years of the program required us to hire some sophomores who somewhat lacked the maturity and organizational skills of the upper-classmen. The mentees and mentors were given pre and post surveys with several questions to assess their level of satisfaction with the program as well as learn about their study habits. Table 4 summarizes some example results of the post survey given in 2016. As can be seen, majority of the students expressed satisfaction with the program and benefited from it. However, the continuing engagement of the students and keeping their interest in the mentoring program presented challenges. In addition, recruitment of mentors with the right academic stature and personality traits was a challenge. As a result, there were variations in survey results from year to year emanating from the qualifications and enthusiasm of the mentors.

Table 4: How satisfied or dissatisfied are you with each of the items below?

\begin{tabular}{|c|c|c|c|c|}
\hline $\mathrm{N}=87$ & Dissatisfied & $\begin{array}{c}\text { Somewhat } \\
\text { Satisfied }\end{array}$ & Satisfied & $\begin{array}{c}\text { Very } \\
\text { Satisfied }\end{array}$ \\
\hline $\begin{array}{l}\text { Your mentor's ability to answer your questions about the } \\
\text { engineering curriculum }\end{array}$ & 6 & 11 & 49 & 21 \\
\hline $\begin{array}{l}\text { Your mentor's ability to help you understand which engineering } \\
\text { major you may want to pursue }\end{array}$ & 7 & 9 & 52 & 18 \\
\hline Your mentor's ability to create an ongoing relationship & 6 & 17 & 47 & 15 \\
\hline The frequency of contact with your mentor & 10 & 17 & 44 & 17 \\
\hline The opportunities for contact with other mentees in the program & 9 & 15 & 47 & 14 \\
\hline The quality of the mentoring program activities & 6 & 16 & 48 & 16 \\
\hline Your overall satisfaction with your assigned mentor & 6 & 14 & 46 & 21 \\
\hline $\begin{array}{l}\text { Your overall satisfaction with all aspects of the mentoring } \\
\text { program. }\end{array}$ & 9 & 13 & 48 & 17 \\
\hline
\end{tabular}


The peer-mentoring program also included periodic visits by the engineers from local companies. Several students attended the organized events and interacted with the engineers to form a better idea about the engineering profession. Many of the engineers shared their educational experiences, gave insightful advice and tips on time management and priorities. The casual interaction with the visiting engineers after the Q\&A sessions typically received high marks from the mentees in attendance.

The mentors also encouraged their mentees to participate in student design teams and professional organizations based on their area of interest. The School of Engineering currently has 36 professional organizations and student design teams. These teams and organizations participate in regional, national, and international competitions and meetings. Participation in professional organizations give students an excellent opportunity for hands-on experience in "doing" engineering as well as for connecting with the engineering community. Each group usually has around 15-20 active participants. The participation rate in student chapters of the national professional organizations is even higher. These organizations encourage freshmen to get involved in various professional and community projects they conduct. The mentors, many of whom are members of professional societies and design teams, helped us increase the rate at which the freshmen participated in student organizations. As a result, we have a higher rate of freshman participation in several student organizations.

\section{Tutoring Services}

In addition to the ES, engineering majors in the mathematics ES and Peer-Mentoring programs had access to both face-to-face and online tutoring services provided by undergraduate engineering peers. On average, 60-70 students took advantage of the tutoring services every semester. The utilization of the tutors peaked especially before Calculus I and Calculus II exams. As a result, the service hours are extended during those critical weeks to make sure that the students received the support they needed to succeed. The tutors periodically communicated with the ES leaders throughout the semester so they were well informed about the topics discussed in the regular lectures as well as ES session practice problems. The tutor logbooks are updated every week and maintained on a cloud drive so their notes in regards to the topics students were having difficulty with can be shared with the ES leaders and instructors. No surveys were given about the tutoring services, but the logbook contained information on how many students utilized the services on a daily basis.

\section{Freshmen Engineering Course}

The impact of redesigning the freshman engineering course also facilitated the engagement of freshmen. The course that was originally taught by an adjunct faculty who had significant industrial experience as a motivational course and lacked focus was converted to a team-taught course. A team of faculty members with proven teaching skills from four engineering majors 
offered in the school claimed ownership of the course and developed four project-based modules. Four sections of the 3-credit hour course is offered every fall and spring as a freshman seminar course that also helps with student's acclimation to college life and institutional culture. The instructors rotate between sections and teach technical background material directly relevant to their hands-on projects thereby not only giving students a chance to meet a faculty member from each department, but also learn from an expert in the field. The detailed impact of the new freshman engineering course is discussed in a separate paper published earlier [2].

The new form of the course not only made a positive impact and improved student performance, but also allowed us to offer another section later to introduce engineering to all majors in the university. The instructional modules taught by some of the best faculty members from different departments along with small discipline specific projects in each module helped us engage students better. On average, more than four fifths of the students passed the course with a grade of $\mathrm{C}$ or better, with a small percentage not succeeding in the course in the new format.

Furthermore, the number of As and Bs showed improvement over the recent academic years due to new format allowing us to better connect with the motivated students. Table 5 summarizes the performance of the students over the last four academic years. This is a noteworthy gain provided by the implemented changes as compared to the old version of the course offered in the 2012-13 academic year.

Table 5: Freshman Engineering Problem Solving Course Performance Summary

\begin{tabular}{|l|c|c|c|c|}
\hline & $\begin{array}{l}\text { Number of } \\
\text { students }\end{array}$ & $\begin{array}{l}\text { Proportion of students } \\
\text { who earned grades of } \\
\text { A, B, or C }\end{array}$ & $\begin{array}{l}\text { Proportion of students } \\
\text { who earned grades of A } \\
\text { or B }\end{array}$ & $\begin{array}{l}\text { Proportion of } \\
\text { students who failed } \\
\text { or withdrew }\end{array}$ \\
\hline Spring 2017 & 128 & 0.892 & 0.612 & 0.108 \\
\hline Fall 2016 & 188 & 0.911 & 0.647 & 0.089 \\
\hline Spring 2016 & 120 & 0.889 & 0.630 & 0.111 \\
\hline Fall 2015 & $199 * *$ & 0.917 & 0.653 & 0.829 \\
\hline Spring 2015 & 117 & 0.830 & 0.479 & 0.094 \\
\hline Fall 2014 & 129 & 0.814 & 0.527 & 0.062 \\
\hline Spring 2014 & 72 & 0.805 & 0.403 & 0.042 \\
\hline Fall 2013 & 74 & 0.730 & 0.405 & 0.040 \\
\hline Spring 2013 & $39 *$ & 0.487 & 0.307 & 0.282 \\
\hline Fall 2012 & 71 & 0.803 & 0.507 & 0.100 \\
\hline
\end{tabular}

* One section of the course was not offered due to unavailability of the instructor.

**An additional section open to undeclared engineering majors is included

\section{Conclusions and Future Directions}

Our integrated approach showed promising results in terms of improving student performance in Calculus I and II and engaging freshmen to the engineering community and profession. The improved performance and engagement in the freshman year definitely contributed to higher retention rates. A positive freshman year experience particularly in early mathematics courses and engagement with campus engineering community sets a solid foundation for and instills confidence in tackling future course work. The following pertinent statistics are observed about 
the undergraduate enrollment numbers and the number of undergraduate degrees awarded by the school of engineering before and after the implementation of this project.

Table 6: Undergraduate Enrollment and Degrees Awarded

\begin{tabular}{|c|c|c|c|c|}
\hline $\begin{array}{c}\text { Academic Year } \\
\text { (AY) }\end{array}$ & $\begin{array}{c}\text { Number } \\
\text { Enrolled }\end{array}$ & $\begin{array}{c}\text { Degrees } \\
\text { Awarded }\end{array}$ & $\begin{array}{c}\text { \% increase in } \\
\text { enrollment as } \\
\text { compared to } \\
\text { prior year }\end{array}$ & $\begin{array}{c}\text { \% increase in } \\
\text { degrees awarded } \\
\text { as compared to } \\
\text { prior year }\end{array}$ \\
\hline $\mathbf{2 0 1 1 - 2 0 1 2}$ & 1004 & 194 & & 21.1 \\
\hline $\mathbf{2 0 1 2 - 2 0 1 3}$ & 1088 & 235 & 8.4 & \\
\hline & & & & 28.4 \\
\hline $\mathbf{2 0 1 5 - 2 0 1 6}$ & 1451 & 229 & 9.5 & 8.2 \\
\hline $\mathbf{2 0 1 6 - 2 0 1 7}$ & 1589 & 294 & 1.3 & \\
\hline $\mathbf{2 0 1 7 - 2 0 1 8}$ & 1609 & 318 & & \\
\hline
\end{tabular}

As can be seen in Table 6 above, the percentage increase in enrollment between 2012-2013 (pre implementation AY) and 2016-2017 (post implementation AY) is $1.1 \%(9.5 \%-8.4 \%)$. During the $5^{\text {th }}$ year of the project, two yearlong serious state budget impasses made a huge impact on the state's public university enrollments. As a result, our enrollment growth slowed down significantly and resulted in only a $1.3 \%$ growth as compared to the prior year. However, the percentage increase in the number of degrees awarded corresponding to the pre implementation and post implementation periods improved by $7.3 \%$ $(28.4 \%-21.1 \%)$. Furthermore, despite a noteworthy drop in enrollment, the number of degrees awarded in year 5 increased by $8.1 \%$ as compared to the fourth year of project implementation. We believe that these positive changes are observed as a result of the project activities that were aimed at engaging freshmen admitted in 2013 and 2014 and helping them succeed in their first year of studies.

As a result of this project, the university has decided to implement the peer-facilitated mathematics ES method campus-wide for all sections of Calculus I. The course is typically taken by all STEM majors including engineering. This is an important step towards sustainability of the ES method that will have an impact on the institution's retention rates. The pilot project is initially funded for 3 years, coordinated between the mathematics department and the school of engineering. If the project results are as promising as observed in this project the university will institutionalize the ES approach.

\section{Acknowledgements}

The project is supported through National Science Foundation Grant Number 1317651. 


\section{References}

[1] National Science Board. The Science and Engineering Workforce: Realizing America's Potential, Publication NSB 03-69, 2003.

[2] Augustine, N. "Rising Above the Gathering Storm: Energizing and Employing America for a Brighter Economic Future", Committee on Science, Engineering, and Public Policy (COSEPUP), 2007.

[3] Herzog, S. "Measuring Determinants of Student Return vs. Dropout/Stopout vs. Transfer: A First-to-Second Year Analysis of New Freshmen", Research in Higher Education, pp. 883-928, December 2005.

[4] Krauss, R., Fries, R., Karacal, C. "Evaluating the Impact of a Revised Introductory Engineering Course: Student Retention and Success as an Indicator" ASEE Annual Conference Proceedings, 2016.

[5] Agustin, Z., Agustin, M., Pelekanos G., Karacal, C. "A holistic student-centered approach to retaining and graduating engineers" ASEE Annual Conference Proceedings, 2016. 